\title{
Electrochemical Determination of Diuron in Soil Using a Nanocrystalline Cellulose Modified Carbon Paste Electrode
}

\author{
MbokouFoukmeniok Serge ${ }^{1,2}$, KarangaYssouf $^{2}$, BakoYiborFabrice Roland $^{2}$, Tapsoba Issa, ," Sakande \\ Fadilatou $^{3}$, KoulibalyBazoumana $^{3}$, Somda Irenée ${ }^{4}$, TonleKenfack Ignas ${ }^{1}$ and Ngameni Emmanuel ${ }^{5}$ \\ ${ }^{1}$ Electrochemistry and Chemistry of Materials, \\ Department of Chemistry, University of Dschang, P.O. Box 67 Dschang, Cameroon \\ ${ }^{2}$ Laboratoire de Chimie Analytique Environnementale et Bio-Organique, Département de Chimie, \\ Université Ouaga I Pr Joseph KI-ZERBO, 03 BP 7021 Ouagadougou 03, Ouagadougou, Burkina Faso \\ ${ }^{3}$ Institut de l'Environnement et de Recherches Agricoles (INERA), Programme Coton, 01 BP 208 \\ Bobo-Dioulasso 01, Burkina Faso \\ ${ }^{4}$ Laboratoire de Phytopathologie, Université Polytechnique de Bobo-Dioulasso, Burkina Faso \\ ${ }^{5}$ Laboratory of Analytical Chemistry, Faculty of sciences, University of Yaoundé I, P.O. Box 812 \\ Yaoundé, Cameroon \\ "E-mail: issa.tapsoba@gmail.com, issa.tapsoba@univ-ouaga.bf
}

doi: $10.20964 / 2021.05 .31$

Received: 9 April 2020 / Accepted: 31 August 2020 / Published: 31 March 2021

An electrochemical sensor based on nanocrystalline cellulose (NC) modified carbon paste electrode (CPE) was developed for the electrochemical detection of diuron in soil samples. Energy dispersive Xray spectroscopy (EDX) and Scanning electron microscopy (SEM) were used for the elemental and morphological characterization of elaborated CPEs, respectively. Electrochemical studies of diuron using the elaborated CPE were performed by cyclic voltammetry (CV) and square wave voltammetry (SWV). The NC-CPE showed an enhanced electrochemical response, with sensitivity 2.3-fold higher than the signal obtained at the unmodified CPE. Key analytical parameters such as $\mathrm{pH}$, scan rate, and the amount of $\mathrm{NC}$ in the carbon paste were investigated and optimized. Excellent results were obtained with a linear range from 4.2 to $47 \mu \mathrm{mol} / \mathrm{L}$ with a detection limit (LOD) of $0.35 \mu \mathrm{M}(\mathrm{S} / \mathrm{B}=3)$. An application of the proposed method to enriched soil samples resulted in a recovery of $96 \%$, showing good stability, reproducibility and reliability of tested sensors.

Keywords: Diuron, carbon paste electrode, cellulose, voltammetry, detection.

\section{$\underline{\text { FULL TEXT }}$}

(C) 2021 The Authors. Published by ESG (www.electrochemsci.org). This article is an open access article distributed under the terms and conditions of the Creative Commons Attribution license (http://creativecommons.org/licenses/by/4.0/). 